\title{
Prognostic value of endoglin-assessed microvessel density in cancer patients: a systematic review and meta-analysis
}

\author{
Jinguo Zhang ${ }^{1,2}$, Lingyun Zhang ${ }^{1,2}$, Qunbo Lin ${ }^{1,2}$, Weimin Ren ${ }^{1,2}$ and Guoxiong Xu $\mathbf{u}^{1,2}$ \\ ${ }^{1}$ Center Laboratory, Jinshan Hospital, Fudan University, Shanghai 201508, China \\ ${ }^{2}$ Department of Oncology, Shanghai Medical College, Fudan University, Shanghai 200032, China
}

Correspondence to: Guoxiong Xu, email: guoxiong.xu@fudan.edu.cn

Keywords: cancer; CD105; disease-free survival; overall survival; prognosis

Received: July 17, $2017 \quad$ Accepted: October 30, $2017 \quad$ Published: December 21, 2017

Copyright: Zhang et al. This is an open-access article distributed under the terms of the Creative Commons Attribution License 3.0 (CC BY 3.0), which permits unrestricted use, distribution, and reproduction in any medium, provided the original author and source are credited.

\section{ABSTRACT}

Background: Endoglin (ENG, CD105), an auxiliary receptor for several TGF- $\beta$ superfamily ligands, is constitutively expressed in tumor microvessels. The prognostic value of ENG-assessed microvessel density (MVD) has not been systemically analyzed. This meta-analysis reviews and evaluates the association between ENG expression and prognosis in cancer patients.

Materials and Methods: Thirty published studies involving in 3613 patients were included after searching of PubMed, Web of Science, and EMBASE. The pooled hazard ratios (HRs) and $95 \%$ confidence intervals (CIs) for overall survival (OS), diseasefree survival (DFS), and cancer-specific survival (CSS) were calculated using randomeffects models. The publication bias was detected by a Begg's test and Egger's test. The outcome stability was verified by sensitivity analysis.

Results: The high ENG-assessed MVD was significantly associated with poor OS (HR = 2.14, 95\% CI 1.62-2.81; $P<0.001)$, DFS (HR = 3.23, 95\% CI 2.10-4.95; $P<0.001)$, CSS (HR = 3.33, 95\% CI 1.32-8.37; $P<0.001)$. Furthermore, subgroup analysis revealed that the association between the overexpression of ENG in tumor microvessels and the outcome endpoints (OS or DFS) were also significant in the Asians and Caucasians patients with different cancer types.

Conclusions: ENG of tumor microvessels is a predictor of poor OS, DFS and CSS and may be a prognostic marker of patients with cancer.

\section{INTRODUCTION}

Cancer have become a major public problem worldwide and the second-largest killer in the United States of America with 1,688,780 new cancer cases and 600,920 new deaths in 2017 [1]. Angiogenesis, a hallmark of cancer, is a crucial step for tumor growth and plays an important role in cancer metastasis. Hence, blocking tumor angiogenesis is a strategy for cancer treatment. Many efforts have focused on finding specific angiogenic markers that can be exploited by vascular targeting drugs over the last few decades [2]. The counting of microvessel density (MVD) is one of the most representative methods to quantify angiogenesis in human cancer tissues [3]. This method requires vascular endothelium markers to visualize microvessels detected by immunohistochemistry (IHC). In addition, there is increasing evidences to show that MVD determination in human cancer specimens is significantly associated with patients outcome [4].

Endoglin (ENG), also known as CD105, HHT1 and ORW1, is a homodimeric transmembrane glycoprotein. The relationship between ENG and cancer has been shown $[5,6]$. It is highly expressed in activated vascular endothelial cells but weakly or not at all expressed in normal quiescent vessels, and therefore, it has been suggested as an important angiogenesis marker [7]. Indeed, the recent studies indicate that targeting ENG suppresses tumor angiogenesis [8-10]. ENG is an auxiliary receptor of transforming growth factor- $\beta$ (TGF- $\beta$ ) that binds to TGF- $\beta 1$ and TGF- $\beta 3$ [11]. It modulates TGF- $\beta$ signaling by interacting with type I and type II TGF- $\beta$ receptor. In human malignancies, ENG is expressed in intratumoral vessels and peritumor, which up-regulated by hypoxia and TGF- $\beta$ stimulation [12]. These features have made 
it become a prime maker for prognosis, tumor imaging, and anti-angiogenesis therapy. Furthermore, many studies have found that ENG may act as a prognostic biomarker to predict patient outcome and has better value than traditional vascular markers, such as vascular endothelial growth factor (VEGF), CD31, and von Willebrand factor [13-15].

Most studies show that high MVD, determined by ENG, seems to correlate with a poor survival in patients with cancer [13-40]. However, others show a conflicting result $[41,42]$. To date, the reliability and degree of the prognostic value of ENG-assessed MVD in human solid tumor have not been systemically analyzed. In view of the limited samples and discrete outcomes in individual studies, we performed a comprehensive meta-analysis to assess the prognostic value of elevated ENG-stained microvessels in human malignances.

\section{RESULTS}

\section{Study selection and characteristics}

Using the pre-defined search strategy, a total of 1757 articles were retrieved from PubMed, Web of Science, and EMBASE databases (Figure 1). After removed duplicate, screened and assessed for eligibility, a total of 30 studies encompassing 3613 patients with cancer were included in this meta-analysis. The median of sample size was 101 with a wide range from 36 to 929 . All the included studies cover a wide range of race, region, and cancer type. Among all cohorts, European (53.33\%) and Asian (36.66\%) countries were the major source regions of literatures, followed by the USA $(10.01 \%)$. We then evaluated these publications and found many types of cancers in the studies, including head and neck cancer (6 studies), esophagus cancer (3 studies), breast cancer (3 studies), colorectal cancer (3 studies), pancreatic cancer (2 studies), cervical cancer (2 studies), prostate cancer ( 2 studies), renal cancer ( 2 studies), gastric cancer (2 studies), ovarian cancer (1 study), urothelial cancer (1 study), glioblastoma (1 study), endometrial cancer (1 study), lung cancer (1 study). Among these studies, 21 studies had the data of OS, 11 studies had the data of DFS, and 3 studies had the data of CSS. The main characteristics of the included studies were shown in Table 1 .

The quality of the 30 eligible studies was assessed by the NOS. The quality scores in total ranged from 6 to 9 , indicating a highly methodological quality of included studies (Table 2).

\section{Association of ENG-assessed MVD on survival and heterogeneity}

The effect of high ENG-assessed MVD on OS was evaluated in 21 studies with 2712 patients. A random effects model was utilized to calculate the pooled HRs and
95\% CIs because of the significant heterogeneity among studies $\left(\mathrm{I}^{2}=62.1 \%, P=0.000\right)$. The results showed that a high ENG-assessed MVD was associated with poor OS in cancer patients $(\mathrm{HR}=2.14,95 \%$ CI $1.62-2.81, P<0.001)$ (Figure 2).

The effect of high ENG-assessed MVD on DFS was evaluated in 11 studies with 1944 patients. A random effects model was applied to calculate the pooled HRs and 95\% CIs because of the significant heterogeneity among studies $\left(\mathrm{I}^{2}=60.5 \%, P=0.005\right)$. The results indicated that the overexpression of ENG protein in tumor microvessels was significantly associated with poor DFS in patients with cancer $(\mathrm{HR}=3.23,95 \%$ CI $2.10-4.95, P<0.001)$ (Figure 3A). The effect of high ENG-assessed MVD on CSS was evaluated in 3 studies with 293 patients. Because the heterogeneity test reported the $P$ value of 0.031 and $\mathrm{I}^{2}$ value of $71.3 \%$, a random effects model was applied to calculate the pooled HRs and 95\% CIs. The pooled result showed that patients with high ENG-assessed MVD possessed a significantly shorter CSS compared with those patients with low ENG-assessed MVD (HR = 3.33, 95\% CI 1.32-8.38, $P<0.001$ ) (Figure 3B).

\section{Subgroup analyses of survival and heterogeneity}

In the subgroup analysis of survival by cancer types, we found that high ENG-assessed MVD was associated with poor OS of patients with breast cancer $(\mathrm{HR}=1.68$, 95\% CI 1.26-2.25, $P<0.001)$, esophagus cancer $(\mathrm{HR}=2.46,95 \%$ CI 1.75-3.44, $P<0.001)$, gynecologic cancer $(\mathrm{HR}=3.61,95 \% \mathrm{CI} 1.54-8.48, P=0.003)$, other cancers $(\mathrm{HR}=1.82,95 \% \mathrm{CI} 1.10-3.01, P=0.019)$ (Figure 4A). Furthermore, in the subgroup analysis of survival by the origin of patients, we also found that high ENG-assessed MVD was associated with poor OS of Caucasian $(\mathrm{HR}=1.81,95 \%$ CI $1.28-2.58, P=0.001)$ and Asian $(\mathrm{HR}=2.86,95 \%$ CI $1.96-4.15, P<0.001)$ (Figure 4B). Similarly, in the subgroup analysis of DFS by cancer type, we found that an increased ENG expression in tumor microvessel was associated with poor DFS of patients with head and neck squamous cell carcinomas $(\mathrm{HR}=5.62,95 \%$ CI 3.16-10.00, $P<0.001)$ and other cancers $(\mathrm{HR}=1.88,95 \% \mathrm{CI} 1.42-2.50, P<0.001)$ (Figure 4C). In the subgroup analysis of DFS by the origin of patients, an increased ENG expression in tumor microvessel was associated with shorter DFS of Asian $(\mathrm{HR}=2.96,95 \% \mathrm{CI} 1.72-5.10, P<0.001)$ and Caucasian $(\mathrm{HR}=3.47,95 \%$ CI 1.86-6.48, $P<0.001)$ (Figure 4D).

To further explore the source of the heterogeneity of OS and DFS, a meta-regression analysis was performed with the covariates including publication year, the origin of people, the number of patients, and multivariate analysis. For OS and DFS, none of these covariates could explain a significant source of the heterogeneity, except a multivariate analyses that showed the heterogeneity on DFS $($ Coef $=0.939, P=0.014)$ (Table 3$)$. 
Table 1: Characteristics of studies included in the meta-analysis

\begin{tabular}{|c|c|c|c|c|c|c|c|c|c|c|c|}
\hline Study & Year & Country & Case & Cancer type & $\begin{array}{l}\text { Stage/ } \\
\text { Grade }\end{array}$ & $\begin{array}{l}\text { Cut-off } \\
\text { value }\end{array}$ & $\begin{array}{l}\text { Follow-up } \\
\text { time(range) }\end{array}$ & $\begin{array}{l}\text { Multi } \\
\text { Anal }\end{array}$ & $\begin{array}{l}\text { S of } \\
\text { HR }\end{array}$ & SO & $\begin{array}{l}\text { NOS } \\
\text { score }\end{array}$ \\
\hline Behrem & 2005 & Croatia & 46 & GBT & NR & Mean & NR & no & $\mathrm{SC}$ & OS & 6 \\
\hline Beketic & 2011 & Croatia & 40 & $\mathrm{BC}$ & G1-G3 & ROC & $\begin{array}{l}55.8 \mathrm{~m} \\
(10.3-83.5)\end{array}$ & no & $\mathrm{R}$ & OS & 6 \\
\hline Chen & 2014 & China & 124 & $\mathrm{EsCa}$ & I-IV & Median & NR & no & $\mathrm{SC}$ & OS & 6 \\
\hline Chuang & 2006 & Taiwan & 94 & $\mathrm{TC}$ & I-II & Mean & $44.1 \mathrm{~m}$ & yes & $\mathrm{R}$ & DFS & 6 \\
\hline Dales & 2003 & France & 929 & $\mathrm{BC}$ & G1-G3 & $\begin{array}{l}\text { log-rank } \\
\text { test }\end{array}$ & $\begin{array}{l}11.3 y \\
(6-15)\end{array}$ & no & $\mathrm{SC}$ & OS/DFS & 8 \\
\hline Dassoulas & 2010 & Greece & 99 & $\mathrm{CRC}$ & I-IV & NR & $25.29 \mathrm{~m}(1-63)$ & yes & $\mathrm{SC}$ & CSS & 7 \\
\hline Erdem & 2006 & Turkey & 90 & $\mathrm{EnC}$ & I-IV & Quartiles & $60.5 \mathrm{~m}$ & yes & $\mathrm{SC}$ & OS & 8 \\
\hline El-Gohary & 2009 & American & 50 & $\mathrm{PCa}$ & I-IV & Median & $54.4 \mathrm{~m}$ & no & $\mathrm{SC}$ & OS & 7 \\
\hline Kyzas & 2006 & Greece & 108 & HNSCC & I-IV & Median & $24 \mathrm{~m}$ & yes & $\mathrm{R}$ & OS & 7 \\
\hline Koyama & 2010 & Japan & 132 & $\mathrm{GC}$ & I-III & Median & $\begin{array}{l}65.23 m \\
(1-213)\end{array}$ & yes & $\mathrm{R}$ & DFS & 7 \\
\hline $\mathrm{Li}$ & 2003 & England & 111 & $\mathrm{CRC}$ & $\begin{array}{l}\text { Dukes } \\
\text { A-D }\end{array}$ & Median & $60 \mathrm{~m}$ & yes & $\mathrm{SC}$ & OS & 8 \\
\hline Lin & 2013 & China & 80 & $\mathrm{CC}$ & I-IV & ROC & $86 \mathrm{~m}(2-144)$ & yes & $\mathrm{R}$ & OS & 7 \\
\hline Lovato & 2015 & Italy & 46 & LC & $\begin{array}{l}\text { pT1- } \\
\text { pT4 }\end{array}$ & ROC & $66.9 \mathrm{~m}$ & yes & $\mathrm{R}$ & DFS & 6 \\
\hline Miyata & 2013 & Japan & 122 & $\mathrm{UC}$ & $\begin{array}{l}\text { pT1- } \\
\text { pT4 }\end{array}$ & Mean & $50 \mathrm{~m}(2-250)$ & yes & $\mathrm{R}$ & CSS & 7 \\
\hline Marioni & 2010 & Italy & 108 & $\mathrm{LC}$ & I-IV & ROC & $38.0 \mathrm{~m}$ & no & $\mathrm{R}$ & DFS & 7 \\
\hline Martone & 2005 & Italy & 127 & HNSCC & I-IV & Median & $70.8 \mathrm{~m}(1-174)$ & yes & $\mathrm{R}$ & OS/DFS & 8 \\
\hline Mineo & 2004 & Italy & 51 & NSCLC & I-II & Median & $48.1 \mathrm{~m}(4-150)$ & no & $\mathrm{SC}$ & OS & 6 \\
\hline Martinovic & 2015 & Croatia & 95 & $\mathrm{RC}$ & II & ROC & $54.7 \pm 23.1 \mathrm{~m}$ & yes & $\mathrm{R}$ & OS & 7 \\
\hline Nikiteas & 2007 & Greece & 100 & $\mathrm{GC}$ & I-IV & Median & $32.57 \pm 29.57 \mathrm{~m}$ & yes & $\mathrm{R}$ & OS & 7 \\
\hline Randall & 2009 & American & 173 & $\mathrm{CC}$ & $\mathrm{I}-\mathrm{II}$ & NR & NR & yes & $\mathrm{R}$ & OS & 8 \\
\hline Rau & 2012 & Taiwan & 140 & $\mathrm{BC}$ & I-II & Median & NR & no & $\mathrm{SC}$ & OS & 6 \\
\hline Saroufim & 2014 & France & 102 & $\mathrm{ccRCC}$ & I-IV & Tertiles & $52 \mathrm{~m}(4-90)$ & yes & $\mathrm{R}$ & OS/DFS & 9 \\
\hline Saad & 2005 & American & 75 & $\mathrm{EsCa}$ & I-IV & Median & $27.3 \pm 10.2 \mathrm{~m}$ & yes & $\mathrm{SC}$ & OS & 7 \\
\hline Sakurai & 2014 & Japan & 142 & EsCa & I-IV & Mean & $41 \mathrm{~m}(1-137)$ & no & $\mathrm{SC}$ & OS/DFS & 7 \\
\hline Taskiran & 2006 & Turkey & 51 & $\mathrm{OC}$ & I-IV & Quartiles & $34 \mathrm{~m}$ & yes & $\mathrm{R}$ & OS & 7 \\
\hline Vayrynen & 2016 & Finland & 148 & $\mathrm{CRC}$ & I-IV & ROC & NR & no & $\mathrm{R}$ & DFS & 9 \\
\hline Wikstro & 2002 & Sweden & 72 & $\mathrm{PCa}$ & I-IV & Median & NR & no & $\mathrm{SC}$ & CSS & 8 \\
\hline Yoshitomi & 2008 & Japan & 36 & PanC & I-IV & Mean & NR & no & $\mathrm{SC}$ & OS/DFS & 7 \\
\hline Zvrko & 2009 & Montenegro & 80 & $\mathrm{LC}$ & I-IV & Median & $27 \mathrm{~m}(6-60)$ & yes & $\mathrm{R}$ & DFS & 7 \\
\hline Zhou & 2015 & China & 42 & PDAC & I-IV & Median & NR & no & $\mathrm{SC}$ & OS & 6 \\
\hline
\end{tabular}

Abbreviations: BC, breast cancer; $\mathrm{CC}$, cervical cancer; ccRCC, clear-cell renal cell carcinomas; CRC, colorectal cancer; CSS, cancer-specific survival; DFS, disease-free survival; EnC, endometrial cancer; EsCa, esophageal cancer; GBT, glioblastoma; GC, gastric cancer; HNSCC, head and neck squamous cell carcinoma; HR, hazard ratio; LC, laryngeal carcinoma; m, month; Multi Anal, multivariate analysis; MVD, microvessel density; NOS, Newcastle-Ottawa-Scale; NR, not report; NSCLC, non-small cell lung cancer; OS, overall survival; OC, ovarian cancer; PanC, Pancreatic cancer; PDAC, pancreatic ductal adenocarcinoma; PCa, Prostate cancer; R, reported; RC, rectal cancer; ROC, receiver operating characteristic; SC, survival curve; SO, survival outcome; S of HR, source of HR; TC, tongue cancer; UC, urothelial cancer; y, year.

\section{Publication bias and sensitivity analysis}

The publication bias was evaluated by the Begg's funnel plot and Egger's test. The funnel plot for OS showed that there was no significant asymmetry (Figure 5A) and no significant publication bias was detected using Egger's test $(P=0.486)$. However, the funnel plot for DFS showed slight heterogeneity (Figure $5 \mathrm{~B}$ ) and the results was validated by Egger's test $(P=0.044)$. Therefore, the "Trim and Fill" method was used to adjust for publication bias. Without "deleted studies", the pooled HRs remained stable. 
Next, we performed a sensitivity analysis to validate the robustness of study influences on OS and DFS. The removal of any individual study had no significant effect on the pooled results (Figure 6A and Figure 6B). These data indicated that no individual study was dominated by this meta-analysis.

\section{DISCUSSION}

Current meta-analysis evaluates the prognostic value of ENG-assessed MVD in cancer patients. We collected 30 eligible studies with a total of 3613 patients and found that ENG-assessed MVD was significantly associated with OS, DFS, and CSS of patients with cancer.

Since the first study published in 1995 found the upregulation of ENG protein expression in tumor

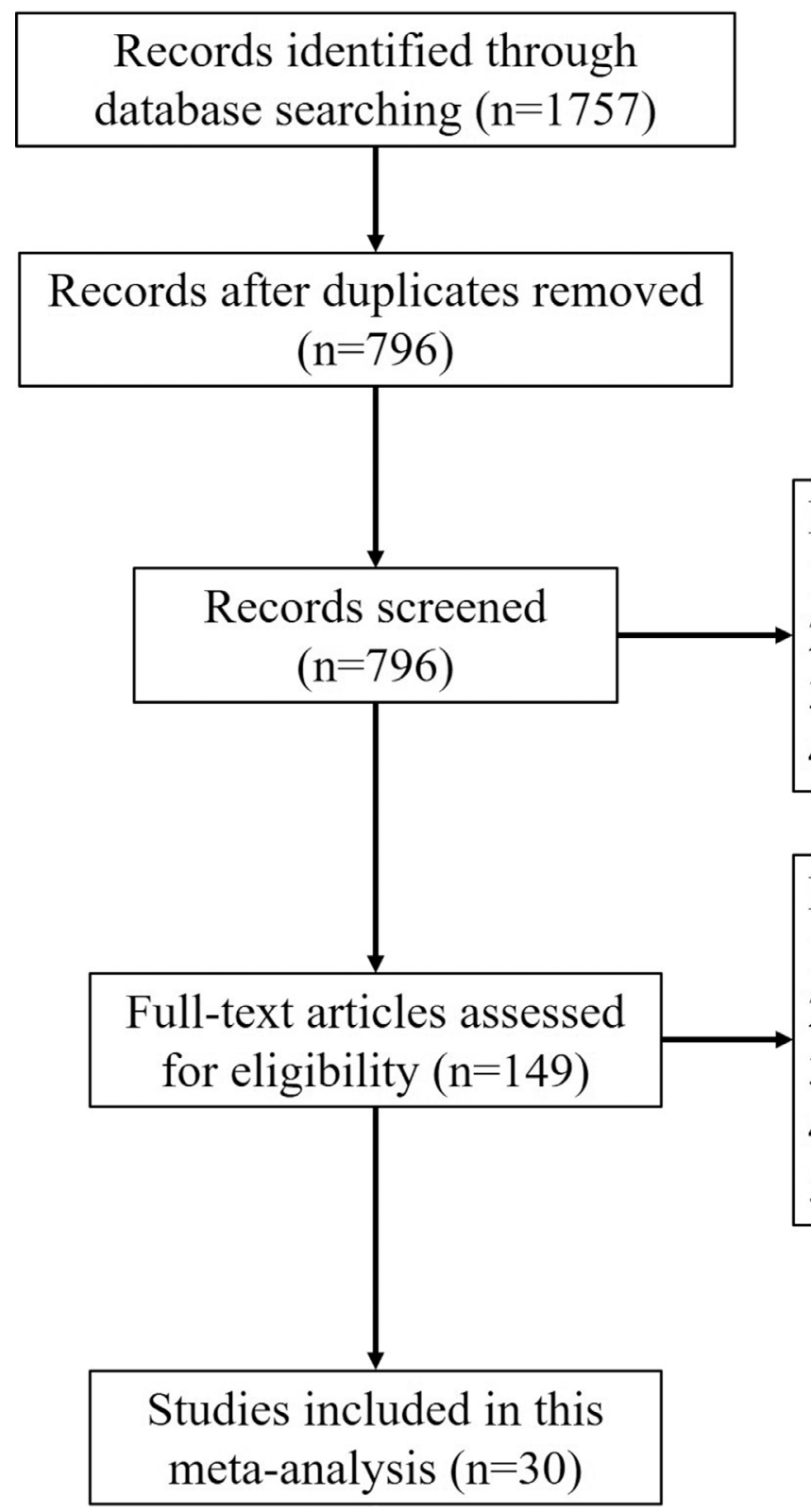

vascular endothelial cells [43], more and more studies have explored the role of ENG on the occurrence and development of tumors. Tumor invasion and metastasis, the most life-threatening events in tumorigenesis, are the major cause of the treatment failure in patients with cancer. Cancer cells shedding into the tumor vascular networks can initiate with the onset of tumor angiogenesis [44], which is permissive for the expansion of a tumor mass. For the anti-angiogenic therapies, much attention was focused on the VEGF family and the receptor tyrosine kinases [45]. In today's anti-angiogenesis drugs, bevacizumab (a humanized monoclonal antibody directed against VEGF), sorafenib and sunitinib (two drugs targeting multiple receptor tyrosine kinases) have been applied to adjuvant chemotherapy with modest survival benefits [46]. In addition, the TGF- $\beta$ signaling pathway is also involved

Records excluded:

1. irrelevant topic $(n=238)$

2. non-English articles $(n=26)$

3. experiment studies $(n=254)$

4. review and meeting abstract $(n=129)$

Records excluded:

1. irrelevant topic $(n=42)$

2. without survival data $(n=35)$

3. inadequate original data $(n=21)$

4. overlapping data $(n=10)$

5. not in tissue sample $(n=11)$

Figure 1: Flow diagram of the study selection procedure. 
Table 2: Methodological assessment by Newcastle-Ottawa scale

\begin{tabular}{|c|c|c|c|c|}
\hline Study & Selection & Comparability & Outcome & Total \\
\hline Behrem & 2 & 2 & 2 & 6 \\
\hline Beketic & 2 & 2 & 2 & 6 \\
\hline Chen & 1 & 2 & 3 & 6 \\
\hline Chuang & 2 & 2 & 2 & 6 \\
\hline Dales & 3 & 2 & 3 & 8 \\
\hline Dassoulas & 3 & 1 & 3 & 7 \\
\hline El-Gohary & 2 & 2 & 3 & 7 \\
\hline Erdem & 4 & 1 & 3 & 8 \\
\hline Huang & 3 & 1 & 2 & 6 \\
\hline Koyama & 4 & 1 & 2 & 7 \\
\hline Kyzas & 2 & 2 & 3 & 7 \\
\hline $\mathrm{Li}$ & 3 & 2 & 3 & 8 \\
\hline Lin & 2 & 2 & 3 & 7 \\
\hline Lovato & 3 & 1 & 2 & 6 \\
\hline Marioni & 3 & 1 & 2 & 6 \\
\hline Martinovic & 3 & 2 & 2 & 7 \\
\hline Martone & 3 & 2 & 3 & 8 \\
\hline Mineo & 2 & 1 & 3 & 6 \\
\hline Miyata & 2 & 2 & 3 & 7 \\
\hline Nikiteas & 2 & 2 & 3 & 7 \\
\hline Randall & 3 & 2 & 3 & 8 \\
\hline Rau & 3 & 2 & 1 & 6 \\
\hline Saad & 3 & 2 & 2 & 7 \\
\hline Sakurai & 2 & 2 & 3 & 7 \\
\hline Saroufim & 3 & 2 & 3 & 8 \\
\hline Taskiran & 3 & 2 & 2 & 7 \\
\hline Vayrynen & 3 & 2 & 4 & 9 \\
\hline Yoshitomi & 2 & 2 & 3 & 7 \\
\hline Zhou & 2 & 2 & 2 & 6 \\
\hline Zvrko & 3 & 2 & 2 & 7 \\
\hline
\end{tabular}

Number indicates a quality score assessed from published articles.

Table 3: Meta-regression analysis of endoglin-assessed MVD in cancer patients

\begin{tabular}{lccccccc}
\hline & \multicolumn{3}{c}{ OS } & & \multicolumn{3}{c}{ DFS } \\
\cline { 2 - 3 } \cline { 6 - 8 } & Coef & Std.Err & $\boldsymbol{P}$ & & Coef & Std.Err & $\boldsymbol{P}$ \\
\hline Publication year & 0.437 & 0.284 & 0.141 & & -0.123 & 0.430 & 0.781 \\
Country & -0.368 & 0.314 & 0.255 & & 0.124 & 0.444 & 0.786 \\
No. of patient & -0.019 & 0.327 & 0.953 & & -0.361 & 0.468 & 0.460 \\
Multivariate & 0.470 & 0.306 & 0.141 & & 0.939 & 0.309 & 0.014 \\
\hline
\end{tabular}

Abbreviations: Coef, coefficient; DFS, disease-free survival; No, number; OS, overall survival; P, a value of probability; Std. Err, standard error. 


\begin{tabular}{|c|c|c|c|}
\hline Study & & & \\
\hline ID & & $\mathrm{HR}(95 \% \mathrm{Cl})$ & Weight \\
\hline Beketic (2011) & & $2.41(1.06,5.50)$ & 4.87 \\
\hline Behrem (2005) & -1 & $1.78(0.86,3.72)$ & 5.35 \\
\hline Chen (2014) & $\underset{1}{\longrightarrow}$ & $2.53(1.43,4.48)$ & 6.28 \\
\hline Dales (2003) & $\infty 1$ & $1.61(1.26,2.36)$ & 7.73 \\
\hline Erdem (2006) & & $5.62(1.51,20.86)$ & 2.92 \\
\hline El-Gohary (2009) & & $1.44(0.57,3.63)$ & 4.37 \\
\hline Kyzas (2006) & & $2.70(1.11,7.50)$ & 4.23 \\
\hline $\mathrm{Li}(2003)$ & & $2.93(1.61,5.33)$ & 6.12 \\
\hline Lin (2013) & & $12.21(3.62,41.16)$ & 3.22 \\
\hline Martone (2005) & & $5.37(2.58,11.79)$ & 5.20 \\
\hline Mineo (2004) & $\rightarrow$ & $1.40(0.58,3.38)$ & 4.58 \\
\hline Martinovic (2015) & & $0.32(0.11,0.93)$ & 3.76 \\
\hline Nikiteas (2007) & ! & $0.52(0.25,1.06)$ & 5.41 \\
\hline Rau (2012) & & $1.38(0.25,7.62)$ & 2.00 \\
\hline Randall (2009) & & $1.62(0.79,3.33)$ & 5.43 \\
\hline Saroufim (2014) & & $3.76(1.63,8.66)$ & 4.81 \\
\hline Saad (2005) & & $2.60(1.39,4.88)$ & 5.95 \\
\hline Sakurai (2014) & & $2.28(1.30,4.01)$ & 6.33 \\
\hline Taskiran (2006) & & $2.45(1.06,5.67)$ & 4.79 \\
\hline Yoshitomi (2008) & -1 & $1.83(0.69,4.82)$ & 4.16 \\
\hline Zhou (2015) & & $4.43(1.01,19.38)$ & 2.48 \\
\hline Overall $(l-$ squared $=62.1 \%, p=0.000)$ & & $2.14(1.62,2.81)$ & 100.00 \\
\hline NOTE: Weights are from random effects analysis & & & \\
\hline $\begin{array}{c}1 \\
0243\end{array}$ & & & \\
\hline
\end{tabular}

Figure 2: Forest plot of studies evaluating the pooled hazard ratios of high endoglin-MVD expression in solid cancers for OS. Values of $\mathrm{I}^{2}$ and $\mathrm{P}$ and the HRs with their $95 \%$ CI of overall survival (OS) in various malignant tumors. A square represents a single study; the centre shows the HR with the horizontal lines denoting the $95 \%$ CIs. The diamond represents the overall $\mathrm{HR}$ for combined results of each study; the centre shows the HR and the extremities show the 95\% CIs. HR, hazard ratio; CI, confidence interval.
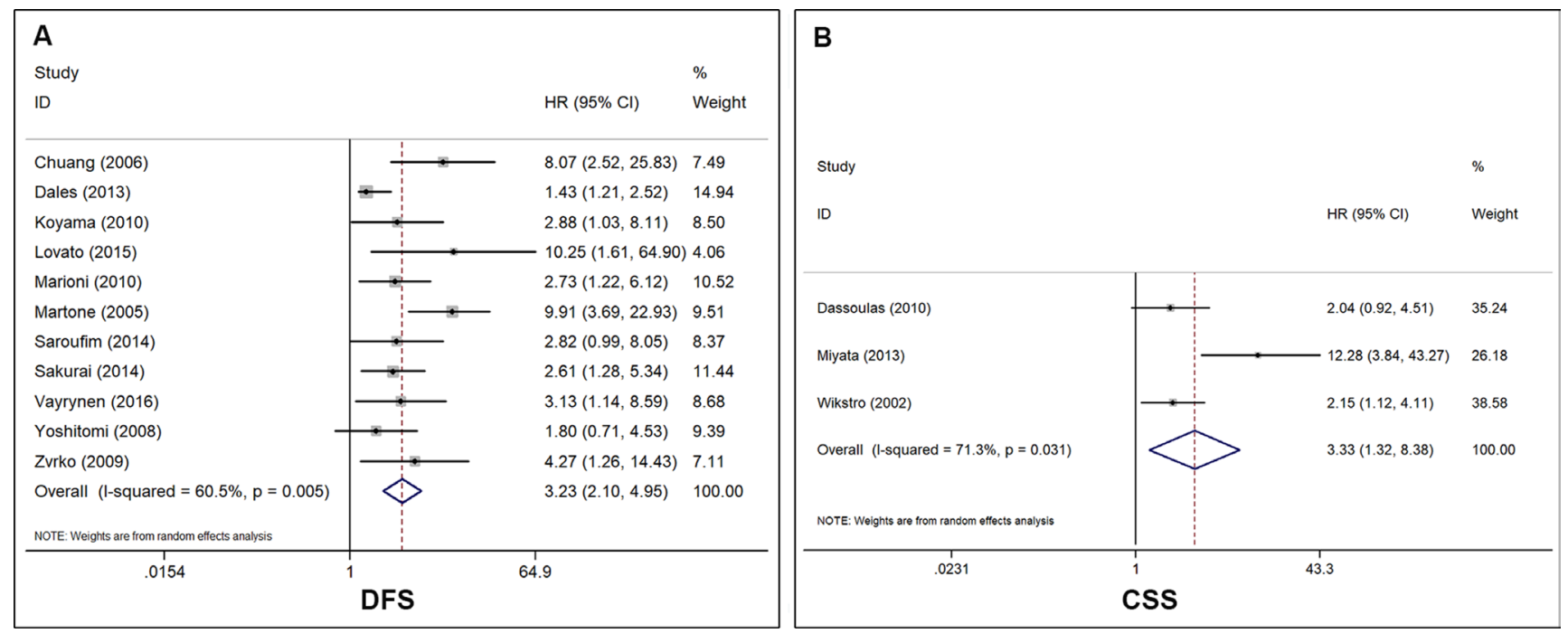

Figure 3: Forest plot of studies evaluating the hazard ratios of high endoglin-MVD in solid cancers for DFS and CSS. (A) Values of $\mathrm{I}^{2}$ and $\mathrm{P}$ and the HRs with their $95 \%$ CI of disease-free survival (DFS). (B) Values of $\mathrm{I}^{2}$ and $\mathrm{P}$ and the HRs with their $95 \%$ CI of cancer-specific survival (CSS). A square represents a single study; the centre shows the HR with the horizontal lines denoting the $95 \%$ CIs. The diamond represents the overall HR for combined results of each study; the centre shows the HR and the extremities show the $95 \%$ CIs. HR, hazard ratio; CI, confidence interval. 
in the differentiation of the endothelial cells and plays an important role in angiogenesis. Unlike these angiogenesis molecules, ENG binds to TGF- $\beta 1$ and $-\beta 3$, interacting with the signaling complex of TGF- $\beta$ receptors types I and II [47]. Mice lacking ENG die from defective vascular development $[48,49]$. In humans, hereditary haemorrhagic telangiectasia type 1 (HHT1), which is characterized by vascular malformations, is attributed to the mutation of the ENG gene [50]. Therefore, ENG-assessed MVD has been correlated with the angiogenesis of malignant tumor.

Unlike pan-endothelial marker, such as CD31, CD34, and von Willebrand factor, CD105 (ENG) is a marker of activated endothelium and participates in angiogenesis [7]. In the last two decades, some studies failed to find a correlation of high MVD with poor prognosis and even had a controversial issue on whether the high MVD in tumor is associated with poor prognosis $[36,51]$. These were most likely due to the use of pan-endothelial markers which were inefficient in recognizing angiogenic endothelial cells. In current meta-analysis, the prognostic value of high ENG-assessed MVD for patients with breast cancer, esophagus cancer, gynecologic cancer, head and neck squamous cell carcinomas was dramatically remarkable. Apart from the prognostic value in cancer patients, ENGassessed MVD is also positively associated with tumor stage, histopathological grade, and lymph node metastasis [52]. Recently, a chimeric monoclonal antibody (TRC105) targeting ENG has entered clinical trial to treat patients with advanced urothelial carcinoma [53], indicating that ENG may be a promising anti-angiogenic target of cancer therapy.

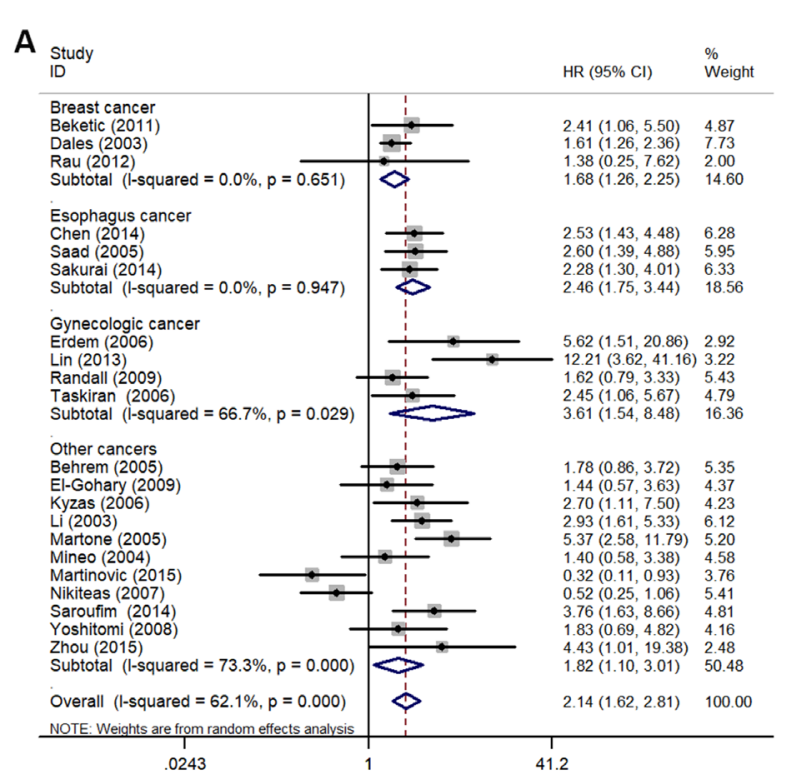

C

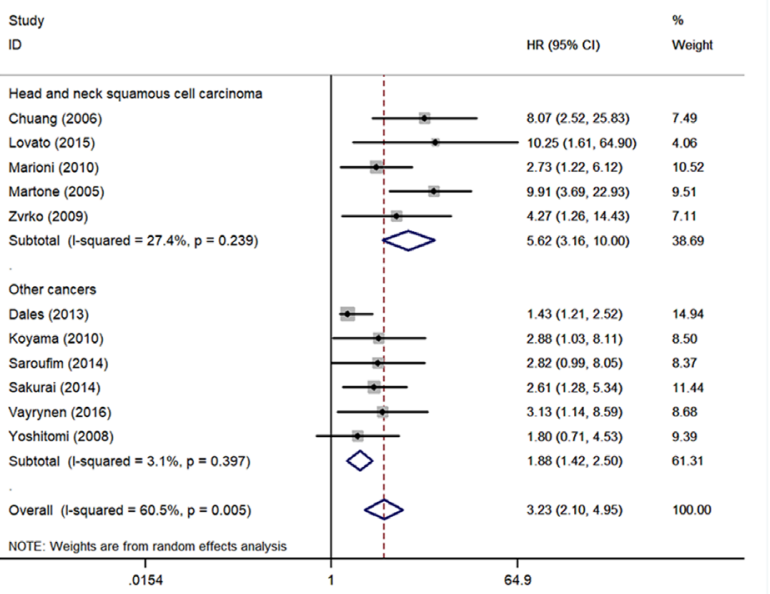

B

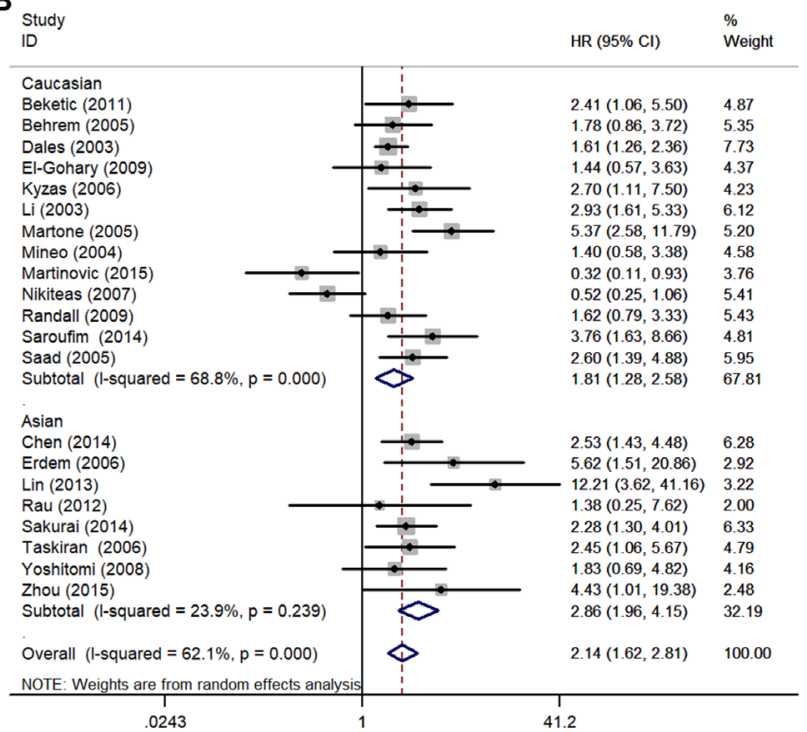

.0243

D

Study $\%$

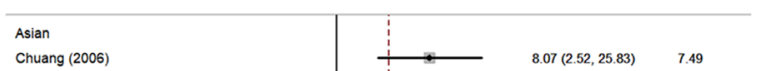

Chuang (2006)

Koyama (2010)

Sakurai (2014)

Yoshitoml (2008)

Subtotal (1-squared $=26.3 \%, p=0.254)$

Caucasian

Dales (2013)

Lovato (2015)

Martone (2005)

Saroufm (2014)

Saroufim (2014)
Vayrynen (2016)

Vayrynen (2019)
Zvrko (2009)

Subtotal $(1-$ squared $=70.6 \%, p=0.002)$

Overall (1-squared $=60.5 \%, p=0.005$ )

NOTE: Weights are from random effects analysis

.0154
$2.88(1.03,8.11) \quad 8.50$

$2.61(1.28,5.34) \quad 11.44$

$1.80(0.71,4.53) \quad 9.39$

$2.96(1.72,5.10) \quad 36.82$

$1.43(1.21,2.52) \quad 14$. $10.25(1.61,64.90) \quad 4.06$ $2.73(1.22,6.12) \quad 10.52$ $9.91(3.69,22.93) \quad 9.51$ $2.82(0.99,8.05) \quad 8.37$ $\begin{array}{ll}2.02(0.99,8.05) & 8.37 \\ 3.13(1.14,8.59) & 8.68\end{array}$ $\begin{array}{ll}3.13(1.14,8.59) & 8.68 \\ 4.27(1.26,14.43) & 7.11\end{array}$ $3.47(1.86,6.48) \quad 63.18$ $3.23(2.10,4.95) \quad 100.00$

Figure 4: Forest plots showing the subgroup analyses of the relationship between the elevated endoglin-MVD expression and OS/DFS. (A) Subgroup analysis of different cancer types for OS. (B) Subgroup analysis of the origin of patients for OS. (C) Subgroup analysis of different cancer types for DFS. (D) Subgroup analysis of the origin of patients for DFS. A square represents a single study; the centre shows the HR with the horizontal lines denoting the $95 \%$ CIs. The diamond represents the overall HR for combined results of subgroup study; the centre shows the HR and the extremities show the $95 \%$ CIs. HR, hazard ratio; CI, confidence interval. 
However, there are some limitations in our metaanalysis. First, the major limitation is the moderate heterogeneity of included studies. Using random effects model and meta-regression analysis, we explored the sources of heterogeneity. In view of the results of subgroup analysis, different cancer types and origin of patients contribute to the heterogeneity of OS and DFS. Second, this meta-analysis included 3613 patients of 30 studies, leading to the limited data in the subgroup analysis. Third, because several HRs were extracted by the survival curves rather than directly obtained from the primary studies, few statistical errors might be inevitable. Fourth, the cut-off values of ENG-assessed MVD were different. The median of MVD was most commonly used among the studies.
Therefore, studies with larger-sample size are needed to determine the most suitable cut-off value. Finally, most of our included studies were retrospective studies, which are more likely to cause the publication bias. Thus, the association between the high ENG-assessed MVD and poor outcome might be overestimated.

In summary, this is the first meta-analysis with strong evidence that increased ENG protein expression in tumor microvessel is correlated to the poor OS, DFS, and CSS. ENG-assessed MVD is valuable prognostic indicator. Due to some limitations in small-sample sized studies, more high-quality, multiple-center, large-sample randomized, controlled trials should be conducted to confirm these results.
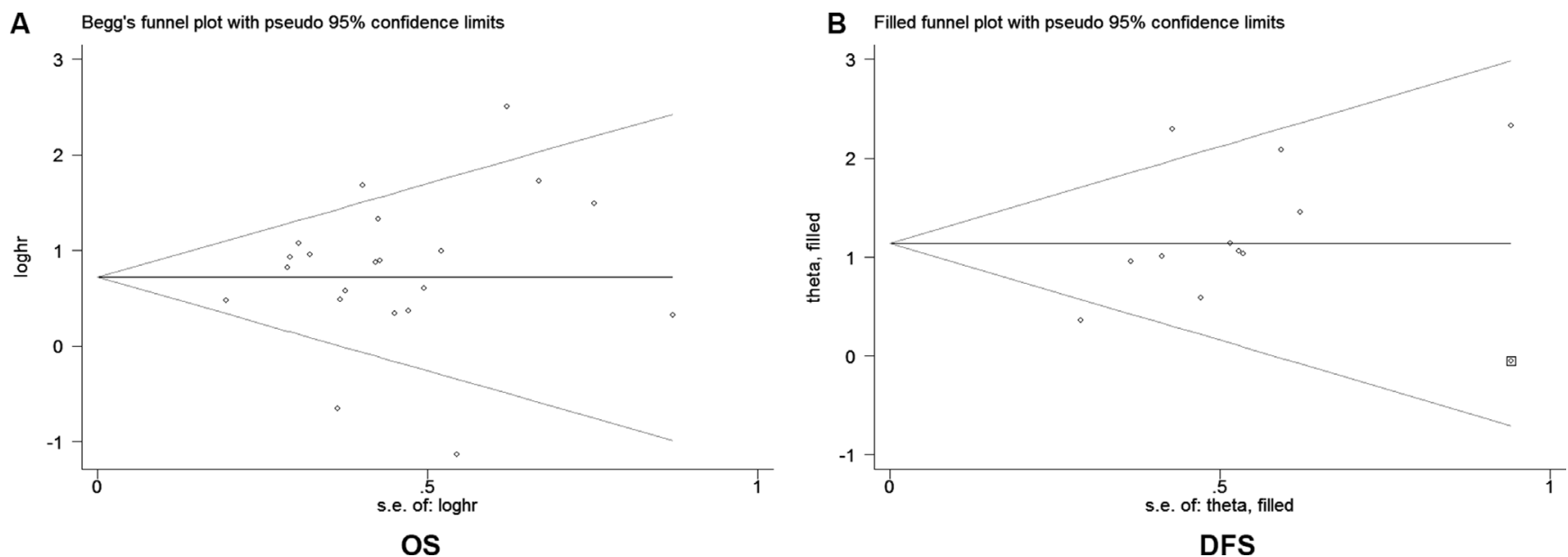

Figure 5: Begg's funnel plot for publication biases. (A) Funnel plot analysis for overall survival (OS). (B) Trim and filled method for disease-free survival (DFS). Circles represent the weight of the studies and square dots represent the added studies. Circles represent the identified studies and square dots represent the added studies after adjustment for publication bias. loghr, logarithm of hazard ratios; s.e., standard error.
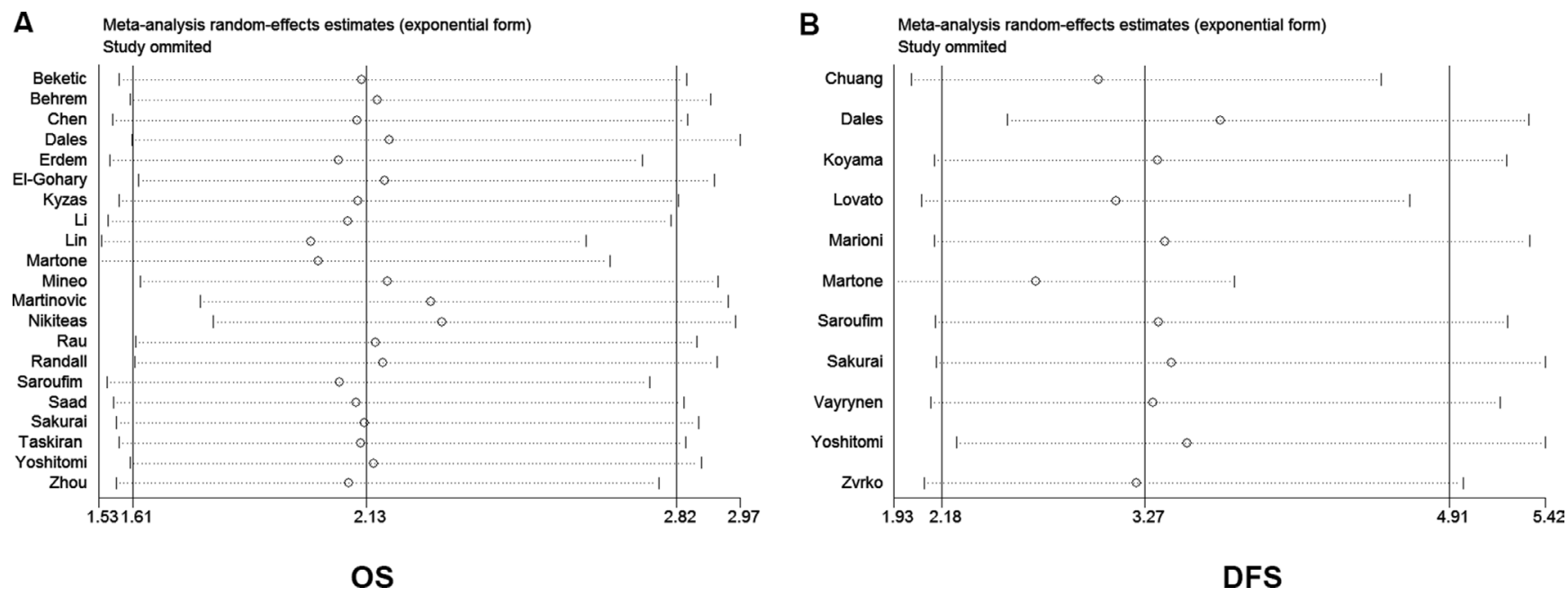

Figure 6: Sensitivity analysis of the meta-analysis. Sensitivity analysis of the effect of the individual study influences on OS and DFS. (A) Sensitivity analysis of overall survival (OS). (B) Sensitivity of disease-free survival (DFS). 


\section{MATERIALS AND METHODS}

Current meta-analysis was done in agreement with the Systematic Reviews and Meta-Analyses (PRISMA) guidelines [54].

\section{Literature searching strategies}

PubMed, Web of Science, and EMBASE databases were thoroughly searched from January 2000 to February 2017 using the search terms (endoglin or ENG or HHT1 or ORW1 or CD105) AND (cancer or tumor or tumour or carcinoma or malignant or malignancy or neoplasm) AND (prognostic or prognosis or survival) AND (mortality or outcome). We also identified potential studies through screening the reference list of identified articles. The comprehensive database search was performed independently by two individuals.

\section{Inclusion and exclusion criteria}

The inclusion criteria were the following: (a) Evaluating of ENG-assessed MVD in tumor tissues for predicting patients prognosis; (b) ENG measurement by immunohistochemistry in tumor tissues; (c) Studies reporting survival data; (d) Studies reporting or containing sufficient data for extracting or calculating the HRs and 95\% CIs; (e) Studies published in English.

The exclusion criteria were the following: (a) Metaanalysis, review, conference abstract, case reports, letters to the editor, and experimental studies without patient data; (b) Inadequate survival data for extracting HRs and 95\% CIs; (c) Duplicate publications or overlapping database; (d) ENG measurement in blood; (e) Articles in non-English.

\section{Methodological assessment}

The quality of a study was assessed by the Newcastle-Ottawa-Scale (NOS) for case-control studies. The NOS categorized into three dimensions including the selection of the study groups, the comparability of the groups, and outcome [55]. The score of the NOS ranged from 0 (lowest) to 9 (highest). The studies with 6 scores or more were identified as high quality studies. The assessment was performed independently by two authors and the final result was achieved by consensus.

\section{Data extraction}

Baseline characteristics of 30 eligible studies was collected, including first author's surname, publication year, origin country, case number, cancer type, detection methods, cut-off value of ENG overexpression, followup period, tumor stage, outcome, multivariate analysis or not, HRs and $95 \%$ CIs in the high ENG expression group versus the low ENG expression group. We analyzed three outcome endpoints: OS, DFS, and CSS. The cumulative recurrence was combined with DFS. The pooled HRs and 95\% CIs were obtained directly from publications or from Kaplan-Meier curves with adequate survival data. If the study only presented Kaplan-Meier curves, we used the Engauge Digitizer V4.1 to obtain survival data and the Tierney's methods [56] to calculate the HRs and 95\% CIs. If the results from both univariate and multivariate analyses, we selected the result of multivariate analysis. Any disagreements between the two researchers were resolved by consensus review.

\section{Statistical analysis}

The pooled HRs and $95 \%$ CIs for three outcome endpoints (OS, DFS, and CSS) were determined by random effects model. The heterogeneity across studies was tested by performing the Chi-square test and by $\mathrm{I}^{2}$ statistics $[57,58]$. If the $P$-value was less than 0.01 and $\mathrm{I}^{2}$ value was more than $50 \%$, the heterogeneity was considered to be significant. $\mathrm{I}^{2}$ values of $<25 \%,<50 \%$, and $>50 \%$ can also be considered as a low, moderate, and severe heterogeneity, respectively. The fixed effects model was performed according to the absence of the heterogeneity. Subgroup analysis and meta-regression were conducted to explore the source of a significant heterogeneity. Publication bias was detected by assessing the asymmetry of funnel plot. In addition, we also conducted Begg's and Egger's tests to quantify publication bias. The Duvaland Tweedie trim-and-fill method [59] was used to calibrate the effect when publication bias existed. The sensitivity analysis was also performed to validate the stability of pooled outcomes. All the statistical analyses were processed via STATA version 12.0 (Stata Corporation, College Station, TX, USA). A $P$-value of less than 0.05 indicated statistical significance for comparison.

\section{CONFLICTS OF INTEREST}

The authors declare no conflicts of interests.

\section{FUNDING}

This work was supported by grants from National Natural Science Foundation of China (81272880), Science and Technology Commission of Shanghai Municipality (124119b1300), Natural Science Foundation of Shanghai (17ZR1404100) and Shanghai Municipal Commission of Health and Family Planning (201640287) to G. Xu.

\section{REFERENCES}

1. Siegel RL, Miller KD, Jemal A. Cancer statistics, 2017. CA: A Cancer Journal for Clinicians. 2017; 67:7-30. https://doi. org/10.3322/caac.21387. 
2. Carmeliet P, Jain RK. Angiogenesis in cancer and other diseases. Nature. 2000; 407:249-57. https://doi. org/10.1038/35025220.

3. Kather JN, Marx A, Reyes-Aldasoro CC, Schad LR, Zollner FG, Weis CA. Continuous representation of tumor microvessel density and detection of angiogenic hotspots in histological whole-slide images. Oncotarget. 2015; 6:19163-76. https://doi.org/10.18632/oncotarget.4383.

4. Nico B, Benagiano V, Mangieri D, Maruotti N, Vacca A, Ribatti D. Evaluation of microvascular density in tumors: pro and contra. Histol Histopathol. 2008; 23:601-7. https:// doi.org/10.14670/hh-23.601.

5. Ilhan N, Gungor H, Gul HF, Eroksuz H. Expression of Endoglin and Vascular Endothelial Growth Factor as Prognostic Markers in Experimental Colorectal Cancer. Anticancer Res. 2016; 36:3953-9.

6. O’Leary K, Shia A, Cavicchioli F, Haley V, Comino A, Merlano M, Mauri F, Walter K, Lackner M, Wischnewsky MB, Crook T, Lo Nigro C, Schmid P. Identification of Endoglin as an epigenetically regulated tumour-suppressor gene in lung cancer. Br J Cancer. 2015; 113:970-8. https:// doi.org/10.1038/bjc.2015.302.

7. Dallas NA, Samuel S, Xia L, Fan F, Gray MJ, Lim SJ, Ellis LM. Endoglin (CD105): a marker of tumor vasculature and potential target for therapy. Clin Cancer Res. 2008; 14:19317. https://doi.org/10.1158/1078-0432.CCR-07-4478.

8. Karzai FH, Apolo AB, Cao L, Madan RA, Adelberg DE, Parnes H, McLeod DG, Harold N, Peer C, Yu Y, Tomita Y, Lee MJ, Lee S, et al. A phase I study of TRC105 antiendoglin (CD105) antibody in metastatic castration-resistant prostate cancer. BJU Int. 2015; 116:546-55. https://doi. org/10.1111/bju.12986.

9. Rosen LS, Gordon MS, Robert F, Matei DE. Endoglin for targeted cancer treatment. Curr Oncol Rep. 2014; 16: 365. https://doi.org/10.1007/s11912-013-0365-x.

10. Ziebarth AJ, Nowsheen S, Steg AD, Shah MM, Katre AA, Dobbin ZC, Han HD, Lopez-Berestein G, Sood AK, Conner M, Yang ES, Landen CN. Endoglin (CD105) contributes to platinum resistance and is a target for tumorspecific therapy in epithelial ovarian cancer. Clin Cancer Res. 2013; 19:170-82. https://doi.org/10.1158/1078-0432. CCR-12-1045.

11. Perez-Gomez E, Del Castillo G, Juan Francisco S, LopezNovoa JM, Bernabeu C, Quintanilla M. The role of the TGF-beta coreceptor endoglin in cancer. Sci World J. 2010; 10:2367-84. https://doi.org/10.1100/tsw.2010.230.

12. Duff SE, Li C, Garland JM, Kumar S. CD105 is important for angiogenesis: evidence and potential applications. FASEB J. 2003; 17:984-92. https://doi.org/10.1096/fj.020634rev.

13. Taskiran C, Erdem O, Onan A, Arisoy O, Acar A, Vural C, Erdem M, Ataoglu O, Guner H. The prognostic value of endoglin (CD105) expression in ovarian carcinoma. Int $\mathrm{J}$ Gynecol Cancer. 2006; 16:1789-93. https://doi.org/10.1111/ j.1525-1438.2006.00658.x.
14. Saad RS, El-Gohary Y, Memari E, Liu YL, Silverman JF. Endoglin (CD105) and vascular endothelial growth factor as prognostic markers in esophageal adenocarcinoma. Human Pathology. 2005; 36:955-61. https://doi.org/10.1016/j. humpath.2005.06.019.

15. Miyata Y, Sagara Y, Watanabe SI, Asai A, Matsuo T, Ohba K, Hayashi T, Sakai H. CD105 is a more appropriate marker for evaluating angiogenesis in urothelial cancer of the upper urinary tract than CD31 or CD34. Virchows Archiv. 2013; 463:673-9. https://doi.org/10.1007/s00428-013-1463-8.

16. Kyzas PA, Agnantis NJ, Stefanou D. Endoglin (CD105) as a prognostic factor in head and neck squamous cell carcinoma. Virchows Arch. 2006; 448:768-75. https://doi. org/10.1007/s00428-006-0195-4.

17. Lin $\mathrm{H}$, Huang $\mathrm{CC}$, Ou YC, Huang EY, Changchien $\mathrm{CC}$, Tseng $\mathrm{CW}, \mathrm{Fu} \mathrm{HC}$, Wu CH, Li CJ, Ma YY. High immunohistochemical expression of TGF-betal predicts a poor prognosis in cervical cancer patients who harbor enriched endoglin microvessel density. Int J Gynecol Pathol. 2012; 31:482-9. https://doi.org/10.1097/PGP.0b013e31824c23a4.

18. Vayrynen SA, Vayrynen JP, Klintrup K, Makela J, Karttunen TJ, Tuomisto A, Makinen MJ. Clinical impact and network of determinants of tumour necrosis in colorectal cancer. Br J Cancer. 2016; 114:1334-42. https://doi.org/10.1038/bjc.2016.128.

19. Zhou L, Yu L, Ding G, Chen W, Zheng S, Cao L. Overexpressions of DLL4 and CD105 are Associated with Poor Prognosis of Patients with Pancreatic Ductal Adenocarcinoma. Pathol Oncol Res. 2015; 21:1141-7. https://doi.org/10.1007/s12253-015-9937-4.

20. Saroufim A, Messai Y, Hasmim M, Rioux N, Iacovelli R, Verhoest G, Bensalah K, Patard JJ, Albiges L, Azzarone B, Escudier B, Chouaib S. Tumoral CD105 is a novel independent prognostic marker for prognosis in clear-cell renal cell carcinoma. British Journal of Cancer. 2014; 110:1778-84. https://doi.org/10.1038/bjc.2014.71.

21. Behrem S, Zarkovic K, Eskinja N, Jonjic N. Endoglin is a better marker than CD31 in evaluation of angiogenesis in glioblastoma. Croat Med J. 2005; 46:417-22.

22. Chen B, Fang WK, Wu ZY, Xu XE, Wu JY, Fu JH, Yao XD, Huang JH, Chen JX, Shen JH, Zheng CP, Wang SH, Li EM, et al. The prognostic implications of microvascular density and lymphatic vessel density in esophageal squamous cell carcinoma: Comparative analysis between the traditional whole sections and the tissue microarray. Acta Histochemica. 2014; 116:646-53. https://doi.org/10.1016/j. acthis.2013.12.003.

23. Dales JP, Garcia S, Bonnier P, Duffaud F, Andrac-Meyer L, Ramuz O, Lavaut MN, Allasia C, Charpin C. CD105 expression is a marker of high metastatic risk and poor outcome in breast carcinomas: Correlations between immunohistochemical analysis and long-term follow-up in a series of 929 patients. Am J Clin Pathol. 2003; 119:374-80.

24. Dassoulas K, Gazouli M, Theodoropoulos G, Christoni Z, Rizos S, Zisi-Serbetzoglou A, Glava C, Karantanos T, Klonaris C, Karakitsos P. Vascular endothelial growth factor 
and endoglin expression in colorectal cancer. J Cancer Res Clin Oncol. 2010; 136:703-8. https://doi.org/10.1007/ s00432-009-0709-y.

25. Erdem O, Taskiran C, Onan MA, Erdem M, Guner H, Ataoglu O. CD105 expression is an independent predictor of survival in patients with endometrial cancer. Gynecol Oncol. 2006; 103:1007-11. https://doi.org/10.1016/j.ygyno.2006.06.010.

26. Lovato A, Marioni G, Manzato E, Staffieri C, Giacomelli L, Ralli G, Staffieri A, Blandamura S. Elderly patients at higher risk of laryngeal carcinoma recurrence could be identified by a panel of two biomarkers (nm23-H1 and $\mathrm{CD} 105)$ and $\mathrm{pN}+$ status. European archives of oto-rhinolaryngology : official journal of the European Federation of Oto-Rhino-Laryngological Societies (EUFOS) : affiliated with the German Society for Oto-Rhino-Laryngology -. Head Neck Surg. 2015; 272:3417-24. https://doi. org/10.1007/s00405-014-3310-1.

27. Marioni G, Marino F, Blandamura S, D'Alessandro E, Giacomelli L, Guzzardo V, Lionello M, De Filippis C, Staffieri A. Neoangiogenesis in laryngeal carcinoma: Angiogenin and CD105 expression is related to carcinoma recurrence rate and disease-free survival. Histopathology. 2010; 57:535-43. https://doi.org/10.1111/j.1365-2559.2010.03664.x.

28. Martone T, Rosso P, Albera R, Migliaretti G, Fraire F, Pignataro L, Pruneri G, Bellone G, Cortesina G. Prognostic relevance of $\mathrm{CD} 105+$ microvessel density in HNSCC patient outcome. Oral Oncol. 2005; 41:147-55. https://doi. org/10.1016/j.oraloncology.2004.08.001.

29. Sakurai T, Okumura H, Matsumoto M, Uchikado Y, Owaki T, Kita Y, Setoyama T, Omoto I, Kijima Y, Ishigami S, Natsugoe S. Endoglin (CD105) is a useful marker for evaluating microvessel density and predicting prognosis in esophageal squamous cell carcinoma. Anticancer Res. 2014; 34:3431-8.

30. Yoshitomi H, Kobayashi S, Ohtsuka M, Kimura F, Shimizu $\mathrm{H}$, Yoshidome H, Miyazaki M. Specific expression of endoglin (CD105) in endothelial cells of intratumoral blood and lymphatic vessels in pancreatic cancer. Pancreas. 2008; 37:275-81. https://doi.org/10.1097/mpa.0b013e3181690b97.

31. Zvrko E, Mikic A, Vuckovic L, Djukic V, Knezevic M. Prognostic relevance of CD105-assessed microvessel density in laryngeal carcinoma. Otolaryngol Head Neck Surg. 2009; 141:478-83. https://doi.org/10.1016/j.otohns.2009.07.001

32. Koyama Y, Okayama H, Kumamoto K, Saito K, Nakamura I, Ohki S, Takenoshita S. Overexpression of endoglin (CD105) is associated with recurrence in radically resected gastric cancer. Exp Ther Med. 2010; 1:627-33. https://doi. org/10.3892/etm_00000098.

33. El-Gohary YM, Silverman JF, Olson PR, Liu YL, Cohen JK, Miller R, Saad RS. Endoglin (CD105) and vascular endothelial growth factor as prognostic markers in prostatic adenocarcinoma. Am J Clin Pathol. 2007; 127:572-9. https://doi.org/10.1309/X6NXYE57DLUE2NQ8.

34. Beketic-Oreskovic L, Ozretic P, Rabbani ZN, Jackson IL, Sarcevic B, Levanat S, Maric P, Babic I, Vujaskovic Z.
Prognostic significance of carbonic anhydrase IX (CA-IX), endoglin (CD105) and 8-hydroxy-2'-deoxyguanosine (8$\mathrm{OHdG}$ ) in breast cancer patients. Pathol Oncol Res. 2011; 17:593-603. https://doi.org/10.1007/s12253-010-9355-6.

35. Rau KM, Huang CC, Chiu TJ, Chen YY, Lu CC, Liu CT, Pei SN, Wei YC. Neovascularization evaluated by CD105 correlates well with prognostic factors in breast cancers. Exp Ther Med. 2012; 4:231-6. https://doi.org/10.3892/ etm.2012.594.

36. Li C, Gardy R, Seon BK, Duff SE, Abdalla S, Renehan A, O'Dwyer ST, Haboubi N, Kumar S. Both high intratumoral microvessel density determined using CD105 antibody and elevated plasma levels of CD105 in colorectal cancer patients correlate with poor prognosis. Br J Cancer. 2003; 88:1424-31. https://doi.org/10.1038/sj.bjc.6600874.

37. Wikstrom P, Lissbrant IF, Stattin P, Egevad L, Bergh A. Endoglin (CD105) is expressed on immature blood vessels and is a marker for survival in prostate cancer. Prostate. 2002; 51:268-75. https://doi.org/10.1002/pros.10083.

38. Chuang HC, Su CY, Huang HY, Chien CY, Chen CM, Huang CC. High expression of CD105 as a prognostic predictor of early tongue cancer. Laryngoscope. 2006; 116:1175-9. https://doi.org/10.1097/01.mlg.0000224338.56902.28.

39. Randall LM, Monk BJ, Darcy KM, Tian C, Burger RA, Liao SY, Peters WA, Stock RJ, Fruehauf JP. Markers of angiogenesis in high-risk, early-stage cervical cancer: A Gynecologic Oncology Group study. Gynecol Oncol. 2009; 112:583-9. https://doi.org/10.1016/j.ygyno.2008.11.013.

40. Mineo TC, Ambrogi V, Baldi A, Rabitti C, Bollero P, Vincenzi B, Tonini G. Prognostic impact of VEGF, CD31, CD34, and CD105 expression and tumour vessel invasion after radical surgery for IB-IIA non-small cell lung cancer. J Clin Pathol. 2004; 57:591-97. https://doi.org/10.1136/ jcp.2003.013508.

41. Nikiteas NI, Tzanakis N, Theodoropoulos G, Atsaves V, Christoni Z, Karakitsos P, Lazaris AC, Papachristodoulou A, Klonaris C, Gazouli M. Vascular endothelial growth factor and endoglin (CD-105) in gastric cancer. Gastric Cancer. 2007; 10:12-7. https://doi.org/10.1007/s10120-0060401-8.

42. Martinovic Z, Kovac D, Martinovic M. Prognostic Significance of Microvessel Density Determining by Endoglin in Stage II Rectal Carcinoma: A Retrospective Analysis. Gastroenterol Res Pract. 2015; 2015: 504179. https://doi.org/10.1155/2015/504179.

43. Burrows FJ, Derbyshire EJ, Tazzari PL, Amlot P, Gazdar AF, King SW, Letarte M, Vitetta ES, Thorpe PE. Upregulation of endoglin on vascular endothelial cells in human solid tumors: Implications for diagnosis and therapy. Clinical Cancer Research. 1995; 1:1623-34. https://doi.org/

44. Liotta LA, Steeg PS, Stetler-Stevenson WG. Cancer metastasis and angiogenesis: an imbalance of positive and negative regulation. Cell. 1991; 64:327-36.https://doi. org/10.1016/0092-8674(91)90642-C. 
45. Arjaans M, Schroder CP, Oosting SF, Dafni U, Kleibeuker JE, de Vries EG. VEGF pathway targeting agents, vessel normalization and tumor drug uptake: from bench to bedside. Oncotarget. 2016; 7:21247-58. https://doi. org/10.18632/oncotarget.6918.

46. Kerbel RS. Tumor angiogenesis. N Engl J Med. 2008; 358:2039-49. https://doi.org/10.1056/NEJMra0706596.

47. Arthur HM, Ure J, Smith AJ, Renforth G, Wilson DI, Torsney E, Charlton R, Parums DV, Jowett T, Marchuk DA, Burn J, Diamond AG. Endoglin, an ancillary TGFbeta receptor, is required for extraembryonic angiogenesis and plays a key role in heart development. Dev Biol. 2000; 217:42-53. https://doi. org/10.1006/dbio.1999.9534.

48. Carvalho RL, Jonker L, Goumans MJ, Larsson J, Bouwman P, Karlsson S, Dijke PT, Arthur HM, Mummery CL. Defective paracrine signalling by TGFbeta in yolk sac vasculature of endoglin mutant mice: a paradigm for hereditary haemorrhagic telangiectasia. Development. 2004; 131:6237-47. https://doi.org/10.1242/dev.01529.

49. Li DY, Sorensen LK, Brooke BS, Urness LD, Davis EC, Taylor DG, Boak BB, Wendel DP. Defective angiogenesis in mice lacking endoglin. Science. 1999; 284:1534-7.

50. Llorca O, Trujillo A, Blanco FJ, Bernabeu C. Structural model of human endoglin, a transmembrane receptor responsible for hereditary hemorrhagic telangiectasia. J Mol Biol. 2007; 365:694-705. https://doi.org/10.1016/j.jmb.2006.10.015.

51. Kumar S, Ghellal A, Li C, Byrne G, Haboubi N, Wang JM, Bundred N. Breast carcinoma: vascular density determined using CD105 antibody correlates with tumor prognosis. Cancer Res. 1999; 59:856-61.

52. Kong X, Wang Y, Liu S, Xing B, Yang Y, Li Y, Ren Z, Su C, Ma W, Wang R. CD105 Over-expression Is Associated with Higher WHO Grades for Gliomas. Mol Neurobiol. 2016; 53:3503-12. https://doi.org/10.1007/s12035-015-9677-1.
53. Apolo AB, Karzai FH, Trepel JB, Alarcon S, Lee S, Lee MJ, Tomita Y, Cao L, Yu Y, Merino MJ, Madan RA, Parnes HL, Steinberg SM, et al. A Phase II Clinical Trial of TRC105 (Anti-Endoglin Antibody) in Adults With Advanced/ Metastatic Urothelial Carcinoma. Clin Genitourin Cancer. 2017; 15:77-85. https://doi.org/10.1016/j.clgc.2016.05.010.

54. Liberati A, Altman DG, Tetzlaff J, Mulrow C, Gotzsche PC, Ioannidis JP, Clarke M, Devereaux PJ, Kleijnen J, Moher D. The PRISMA statement for reporting systematic reviews and meta-analyses of studies that evaluate health care interventions: explanation and elaboration. PLoS Med. 2009; 6:e1000100. https://doi.org/10.1371/journal. pmed.1000100.

55. Stang A. Critical evaluation of the Newcastle-Ottawa scale for the assessment of the quality of nonrandomized studies in meta-analyses. Eur J Epidemiol. 2010; 25:603-5. https:// doi.org/10.1007/s10654-010-9491-z.

56. Tierney JF, Stewart LA, Ghersi D, Burdett S, Sydes MR. Practical methods for incorporating summary time-to-event data into meta-analysis. Trials. 2007; 8:16. https:/doi. org/10.1186/1745-6215-8-16.

57. Higgins JP, Thompson SG, Deeks JJ, Altman DG. Measuring inconsistency in meta-analyses. BMJ. 2003; 327:557-60. https://doi.org/10.1136/bmj.327.7414.557.

58. Higgins JP, Thompson SG. Quantifying heterogeneity in a meta-analysis. Stat Med. 2002; 21:1539-58. https://doi. org/10.1002/sim.1186.

59. Duval S, Tweedie R. Trim and fill: A simple funnel-plotbased method of testing and adjusting for publication bias in meta-analysis. Biometrics. 2000; 56:455-63. 